\title{
Scalarity and alternatives of Japanese mora (letter)-based minimizers
}

\author{
Osamu Sawada*
}

\begin{abstract}
This paper investigates interpretations of the Japanese mora- (letter-) based minimizer "X.Y.Z"-no "X"-no ji-mo "even the letter "X" of "X.Y.Z".' I argue that this mora/letter-based minimizer has two types, a literal type and a non-literal type, and each type has different semantic characteristics regarding scale structure and computation of alternatives. In the literal type, $X$ corresponds to the first mora of a target "X.Y.Z" and is construed as a minimum on the number scale of moras (among higher scalar alternatives). On the other hand, in the non-literal type it refers to the degree of a main predicate about the target "X.Y.Z" where X is construed as a minimum on the scale of the main predicate. That is, in the non-literal type, scale does not have to do with the number of moras, but with the degree of a predicate. I propose on the basis of the findings that in addition to a local minimizer whose alternatives are lexically activated (Chierchia 2013), there is a global minimizer in natural language, whose alternatives are activated by information contained in the main predicate.
\end{abstract}

Keywords. mora-based minimizer; literal reading; non-literal reading; scalarity; alternatives; local vs. global minimizers

1. Introduction. Many languages have minimizer negative polarity items (NPIs) that include the word "word(s)," such as the Japanese hito-koto-mo 'even one word' or the English a word, as shown in (1):

(1) a. The spokesman didn't say a word about the earthquake. (English)

b. Shachoo-wa jiko-nitsuite hito-koto-mo iwa-naka-tta. (Japanese)

President-TOP accident-about one-CL.word-even say-NEG-PAST

'The company president didn't say a word about the accident.'

However, in Japanese, there is also a minimizer NPI that involves a mora (letter) with the form "X.Y.Z"-no "X"-no ji-mo 'lit. even the mora (letter) "X" of "X.Y.Z".' (I call this a mora or letter-based minimizer.) What is interesting about the mora-based minimizer is that it has not only a literal use, as in (2), but also a non-literal use, as in (3):

(2) (Literal type)

Taro-wa “i.ro.ha”-no "i”-no ji-mo kak-e-nai.

Taro-TOP i.ro.ha-GEN i-GEN letter-even write-can-NEG

"Taro cannot even write the "i" of "i.ro.ha" (Note: "I," "ro," and "ha" are the first three letters of the old-style Japanese hiragana order (a poem.)

(3) (Non-literal type)

\footnotetext{
*I am grateful to Željko Bošković, Wayles Browne, Mitcho Erlewine, Nathan Hamlitsch, Magda Kaufmann, Stefan Kaufmann, Yusuke Kubota, Uli Sauerland, Harumi Sawada, Jun Sawada and the audience at the LSA 2019 for their valuable discussions and comments. This paper is based upon work supported by JSPS (grant number 18K00531). All the remaining errors are of course my own. Author: Osamu Sawada, Mie University (sawada.osamu@gmail.com)
} 
Taro-wa "ge.n.go.ga.ku"-no "ge"-no ji-mo shira-nai.

Taro-TOP linguistics-GEN GE-GEN letter-even know-NEG

'Taro does not know anything about linguistics.'

Example (3) has the following meaning: "Taro does not even have basic knowledge of linguistics"; however, this is not the literal meaning.

Since Bolinger (1972), many important studies have been done on the meaning and distributions of minimizer NPIs and the underlying syntactic, semantic, and pragmatic mechanisms (e.g., Ladusaw 1980; Heim 1984; Lee \& Horn 1994; Krifka 1995; Giannakidou 1998; Lahiri 1998; Chierchia 2013; Csipak et al. 2013, among many others). However, to the best of my knowledge, little attention has been paid to mora- (or letter-) based minimizers like (2) and (3) in the formal semantics literature on minimizers. ${ }^{1}$

What are the differences between literal and non-literal minimizers? How do we interpret the meaning of the non-literal use of a mora-based minimizer? Does the mora-based minimizers have any important characteristics that other regular minimizer NPIs don't have?

In this paper I will first argue that the literal and non-literal types of mora-based minimizer are lexically different and the non-literal interpretation is not a secondary, inferential meaning derived from the literal meaning. I will then argue that each type of mora-based minimizer posits a different semantic mechanism in terms of scalarity and the computation of alternatives. The literal type posits a scale of numbers to moras and construes the first mora to be the minimum on the scale. It also triggers a set of alternatives according to the number scale. In contrast, in the nonliteral type it refers to the degree of a main predicate about the target "X.Y.Z" where X is construed as a minimum on the scale of the main predicate. That is, in the non-literal type, scale does not have to do with the number of moras, but with the degree of a predicate.

I propose that the phenomenon of the non-literal mora-based minimizer suggests that in addition to a local minimizer whose alternatives are lexically activated (Chierchia 2013), there exists a global minimizer in natural language, the alternatives provided by which are activated by information contained in the main predicate. In the final part of the paper I will show that the phenomenon of the non-literal mora-based minimizer can be found in other languages such as Bosnian/Croatian/Serbian, and it is not a language-specific phenomenon.

2. Mora-based minimizers are strict NPIs. The Japanese mora-based minimizers are NPIs in the sense that they cannot appear in a positive environment: ${ }^{2}$

(4) (Literal type)

Taro-wa "i.ro.ha"-no "i"-no ji-mo $\quad$ ???kak-e-ru /kak-e-nai $\}$.

Taro-TOP i.ro.ha-GEN i-GEN letter-even $\{$ write-can-PRES /write-can-NEG

\footnotetext{
${ }^{1}$ Niino 1993 briefly mentions that a mora-based minimizer corresponds to a "frame idiom" (productive idiom), while Akihiro Okajima comments on Niino's (1993) observations with additional examples on a post on his homepage of August 22nd, 1996 (http://www.let.osaka-u.ac.jp/ okajima/menicuita/9608.htm\#22.), but it seems that there have been no serious formal studies of this expression.

${ }^{2}$ In the literal type (=4) the positive sentence can be OK if $m o$ is interpreted as 'also', but in that case, iroha is not obligatory and it is only used to help the hearer understand that $i$ corresponds to a hiragana. In (5) the positive sentence sounds odd even if mo is interpreted as 'also.'
} 
"Taro $\{$ ??can/cannot $\}$ even write the "i"" of "i.ro.ha"

(5) (Non-literal type)

Taro-wa "ge.n.go.ga.ku"-no "ge"-no ji-mo \{??shi-teiru /shira-nai $\}$.

Taro-TOP linguistics-GEN GE-GEN letter-even $\{$ know-STATE $/$ know-NEG $\}$

'Taro \{??knows/does not know $\}$ even "ge" of "ge.n.go.ga.ku".'

More precisely, these are strict NPIs (Giannakidou 2011), in that they are only allowed with negation. For example, they cannot appear in downward entailing or nonveridical environments such as an antecedent of conditionals and question: ${ }^{3}$

(6) (Conditional)

a. ??"I.ro.ha"-no "i"-no ji-mo kak-e-reba juubun-da.

I.ro.ha-GEN i-GEN letter-even write-CAN-COND enough-PRED

'If you can write "i" of "i.ro.ha", then that will be enough.'

b. ??"Ge.n.go.ga.ku"-no "ge”-no ji-mo shi-tteir-eba, juubun-da.

Linguistics-GEN GE-GEN letter-even know-STATE-COND enough-PRED

'If you know "ge" of "ge.n.go.ga.ku", then that will be enough.'

(7) (Question)

a. ??"I.ro.ha"-no "i"-no ji-mo kak-e-ru-no?

I.ro.ha-no i-GEN letter-mo write-can-PRES-Q

'Can you write "i”" of "i.ro.ha"?'

b. ??"Ge.n.go.ga.ku”-no ge-no ji-mo shi-tteiru-no?

Linguistics-GEN GE-GEN letter-even know-STATE-Q

'Do you know ge of "ge.n.go.ga.ku”?'

Note that mo is necessary to form a mora-based minimizer. Since the purpose of this paper is not to consider polarity sensitivity of the mora-based minimizer, we cannot discuss how we analyze the relationship with EVEN and negation, but it seems safe to posit that "X.Y.Z.-no X-no ji" morphosyntactically requires EVEN (which is added to $j i$ 'letter') and negation (which appears in the same clause). ${ }^{4}$

3. Distinction between literal and non-literal uses. Now let us consider the difference between the two types of mora-based minimizers. There are several empirical diagnostics to distinguish between the two types.

3.1 Diagnostic 1: A DEnial TEST. First, these readings can be distinguished based on the interpretation of a denial. In a literal reading, a denial can target the (literal) meaning, while in a non-literal reading, a denial cannot do this.

For example, in (8), if a hearer says Iya, sore-wa uso-da 'No, that's false' in Japanese after

\footnotetext{
${ }^{3}$ As is well known, English minimizers like lift a finger can appear in various non-negative environments including antecedent of conditional or question; in addition, English minimizers are fine with only and the emotive factive verbs (see, e.g. Giannakidou (2011) for an overview of previous studies.)

${ }^{4} \mathrm{We}$ can use sae 'even' instead of $m o$ to create a mora-based minimizer, but for many speakers the use of $m o$ is more frequent and more natural.
} 
(8A), the denial is interpreted as a rejection of the idea that Taro cannot write the letter "i" (hiragana い). The hearer can reply by saying "He can write "i.".

(8) (Literal reading)

A: Taro-wa "i.ro.ha"-no "i”-no ji-mo kak-e-nai.

Taro-TOP i.ro.ha-GEN i-GEN letter-even write-can-NEG

"Taro cannot even write the "i"" of "i.ro.ha"

B: Iya sore-wa uso-da. "i'-wa kak-e-ru-yo.

No that-TOP false-PRED i-TOP write-can-NON.PAST-YO

'No that's false. He can write "i".'

By contrast, in (9), the denial is rejecting the non-literal meaning of A's utterance:

(9) (Non-literal reading)

A: Taro-wa "ge.n.go.ga.ku"-no "ge"-no ji-mo shira-nai.

Taro-TOP linguistics-GEN GE-GEN letter-even know-NEG

'Taro does not know anything about linguistics.'

B: Iya sore-wa uso-da. Sukoshi-wa shi-tteiru-yo.

No that-TOP false-PRED. A bit-Cont.TOP know-STATE-YO

'No that's false. He knows a bit about linguistics.'

Here Speaker B is rejecting to the idea that Taro does not know anything about linguistics.

3.2 DiagnostiC 2: RePlaceABILITY By a CHINESE CHARACTER REPRESENTING MULTI-PLE MORAS. The second diagnostic is concerned with the possibility of the use of a Chinese character with multiple moras. In a literal reading, the $\mathrm{X}$ in "X.Y.Z-no X-no ji" could actually be a single Chinese character with multiple moras. For example, the proper name Keita has three moras (three hiragana ), "ke.i.ta," and is written as 啓太, which consists of two Chinese characters (kanji). In this case, both "ke" or "kei" (啓) could be X for a literal reading:

(10) (Literal type)

a. Keita-wa mada akachan-nanode "ke.i.ta"-no $\{$ ke/kei $\}$-no ji-mo

Keita-TOP still baby-because Keita-GEN ke/kei (啓)-GEN letter-even

kak-e-nai.

write-can-NEG

'Since Keita is still a baby, he cannot even write the "ke"/“kei” (啓) of “Keita” (啓太).'

b. Taro-wa "i.ro.ha"-no "i"-no ji-mo kak-e-nai.

Taro-TOP i.ro.ha-GEN i-GEN letter-even write-can-NEG

"Taro cannot even write the "i"" of "i.ro.ha"

By contrast, only a mora-based formation is possible in a non-literal reading. For example, ronrigaku 'logic' has five moras (ro.n.ri.ga.ku) and is written in three Chinese characters, 論理学 (= ron.ri.gaku). In order to employ this word in a non-literal use of the "X.Y.Z-no X-no ji" expression, $\mathrm{X}$ has to be "ro" (not "ron" (論)): 
(11) (Non-literal type)

Taro-wa ro.n.ri.ga.ku-no $\{$ ro/??ron $\}$-no ji-mo shira-nai.

Taro-TOP logic-GEN ro/ron-GEN letter-even know-NEG

'Taro does not know anything about logic.'

The above diagnostics suggest that at least in Modern Japanese there is a distinction between literal and non-literal readings that manifests in terms of both meaning and formation.

One might now consider the possibility that the non-literal interpretation is pragmatic, derived from a literal mora-based minimizer. Although such a pragmatic inference approach is attractive, it is flawed. For example, in (9A), the non-literal interpretation cannot arise based on a literal interpretation because there is no literal reading in this sentence to begin with (the speaker A, of course, knows that Taro knows the letter "ge"). Furthermore, a purely pragmatic approach also cannot naturally explain the empirical results of the two diagnostics.

3.3 DIFFERENCE BETWEEN MORA-BASED MINIMIZERS AND METALINGUISTIC FOCUS. Before moving onto the more detailed analyses of literal and non-literal mora-based minimizers, let me briefly note that they are different from what is often called metalinguistic focus (Selkirk 1984; Rochemont 1986; Artstein 2004; Li 2017), as exemplified in:

(12) (Context: Both stalagmites and stalactites are salient)

John only brought home a stalagMITE from the cave. (Artstein 2004: :2)

(13) (Mandarin)

A: Libai qu-le Ha'erbing.

Libai go-asp Harbin

'Libai went to Harbin.'

B: Ta qu-le Ha'er[bin $]_{F}$.

he go-asp Harbin

'He went to Har[bin] $]_{F}$ ' (Li 2017: 345)

Metalinguistic focus in (12) and (13) is similar to a mora-based minimizer in that a focus is put below the word level. However, they are different in that the former, but not the latter, has a pragmatic function of correction. Furthermore, unlike metalinguistic focus, with a mora-based minimizer there is a rule that it always targets the first mora of a word. Because of these facts, although there is some similarity between metalinguistic focus and mora-based minimizers, I would like to consider them as distinct phenomena.

4. The meaning and interpretation of the literal type. Let us next investigate the meaning and interpretations of the two types of mora-based minimizer. In this section we will analyze the meaning of the literal type.

4.1 THE KINDS OF VERBS THE LITERAL MORA-BASED MINIMIZER COMBINES WITH. In the literal use of the mora-based minimizer, $j i$ is interpreted literally. Thus, the verbs that are used with the literal type are those that can take $j i$ 'letter' as an object, such as kaku 'write', de-te kuru 'come out/appear' or nai 'not exist':

a. Taro-wa "i.ro.ha"-no "i"-no ji-mo kak-e-nai.

Taro-TOP i.ro.ha-GEN i-GEN letter-even write-can-NEG 
'Taro cannot even write the "i"” of "i.ro.ha".'

b. Uta-ni-wa "shi.be.ri.a"-no "si"-no ji-mo de-te ko-nai.

Song-in-TOP Siberia-GEN si-GEN letter-even out-TE come-NEG

'In the song, even the letter "shi" of "Shiberia" does not come out.' (From BCCWJ-NT corpus)

c. Mohaya kanojo-no nouri-ni-wa "Le.o"-no "le"-no ji-mo

Any longer she-GEN mind-LOC-TOP Leo-GEN le-GEN letter-even

nai-yoo-de-a-tta.

exist.NEG-seem-PRED-BE-PAST

'It seems that there is not even the "le" of "Leo" in her mind any longer.' (From BCCWJ-NT corpus)

In the BCCWJ-NT corpus, we can find the following verbs co-occurring with the literal type of minimizer:

(15) The verbs co-occurs with a literal mora-based minimizer (from BCCWJ-NT corpus): de-te ko-nai 'does not appear', miatara-nai 'cannot find', toujou si-nai 'does not appear', mirarenai 'is not seen', mi-taku-nai 'don't want to see', omoi ukaba-nai 'does not come to mind', nai 'lack'.

Note that the following example with the verb iu 'say' cannot be considered as an example of the literal type of minimizer:

Shushou-wa "ka.i.sa.n"-no "ka"-no ji-mo iwa-na-katta.

Prime minister breakup-GEN KA-GEN letter-even say-NEG-PAST

'The prime minister didn't say anything about a breakup at all.'

This is because $i u$ 'say' cannot take $j i$ 'letter' as its object. Also, the two diagnostics suggests that this sentence belongs to the non-literal reading.

4.2 FORMAL ANALYSIS. Let us now analyze the meaning of the non-literal minimizer. In analyzing the meaning of the literal type, it is necessary to theoretically capture the fact that the minimizer accesses a phonological component of a word and makes the "minimum" element correspond to the first mora of the whole expression. Following Potts (2007), I assume that the linguistic entities are triples, $\langle\Pi ; \Sigma ; \alpha: \tau\rangle$, where $\Pi$ is a phonological representation (phon), $\Sigma$ is a syntactic representation (syn), and $\alpha$ is a semantic representation (sem) of type $\tau$.

Let us consider the meaning of the literal type of mora-based miminizer based on (14a). First, we can represent the lexical information of "i.ro.ha" as follows :

$\langle$ [i.ro.ha]; NP; the (first three words of) Japanese syllabary: $e$ 〉

As with ordinary minimizer NPIs, a mora-based minimizer also has a meaning of "even" (i.e., mo 'even'), which creates a set of alternatives. Following the insights of alternative semantics, I propose that the literal use of " $\alpha$ "-no " $\beta$ "-no $j i$ has an ordinary at-issue meaning, as in (18a), and that it also lexically activates a set of alternatives (i.e., the focus semantic value (Rooth 1992)), as in $(18 b)(\sigma$ stands for mora. \# = number $)$ :

a. $\left[\left[" \alpha "\right.\right.$ "no " $\beta "$ "no ji $\left.\left.\ddot{i}_{l i t}\right]\right]=\lambda P \lambda x . P\left(\beta_{\text {phon }}<_{\text {part.of }} \alpha_{\text {phon }}\right)(x)$ 
(presupposition: $\beta_{\text {phon }}$ is the first $\sigma$ of $\alpha_{\text {phon }}$ )

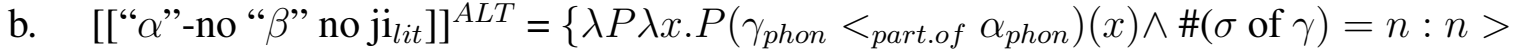
$1\}$

A set of alternatives is created by replacing the focused element $\beta$ (which is the first mora of $\alpha$ ) with elements of the same type (Rooth 1992). I assume that there is also a presupposition that $\beta$ is the first mora of $\alpha$. (19) shows the at-issue propositional meaning and its alternatives. The alternatives in (19) are computed in the same way as the ordinary semantic meaning is computed, that is, in a pointwise manner (Kratzer \& Shimoyama 2002), as shown in (20):

a. [[“i.ro.ha"-no "i"-no $\left.\left.\mathrm{ji}_{l i t}\right]\right]=\lambda P \lambda x . P\left(\mathrm{i}<_{\text {part.of }}\right.$ i.ro.ha $)(x)$

b. [[ "i.ro.ha"-no "i"-no ji $\left.\left.l_{\text {lit }}\right]\right]^{A L T}=\left\{\lambda P \lambda x . P\left(\gamma<_{\text {part.of }}\right.\right.$ i.ro.ha $)(\mathrm{x}) \wedge \#($ mora of $\gamma)=n$ : $n>1\}$

(20) a. at-issue propositional meaning: $\neg$ can(write $(\mathrm{i}<$ part.of i.ro.ha $)($ Taro $))$

b. $\quad$ alternatives: $=\left\{\neg \operatorname{can}\left(\operatorname{write}\left(\gamma<_{\text {part.of }}\right.\right.\right.$ i.ro.ha $)($ Taro $\left.)\right) \wedge \#($ mora of $\left.\gamma)=n: n>1\right\}$

Now, we need to understand the role of mo 'even' in detail. In this paper, I will assume, building on the ideas of Karttunen \& Peters (1979) and Lahiri (1998), that mo morphosyntactically combines with $\mathrm{X}-n o j i$, but in the logical structure it behave as a proposition taking an operator, as shown in:

(21) a. Surface structure (syntax)

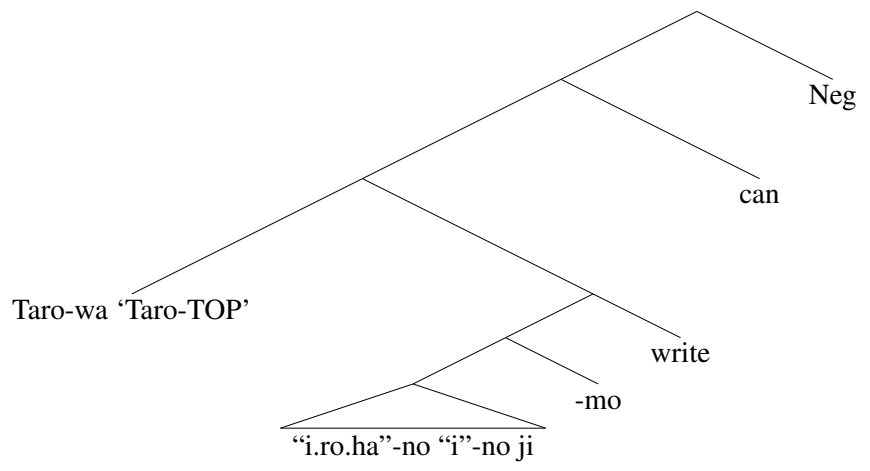

b. Logical structure

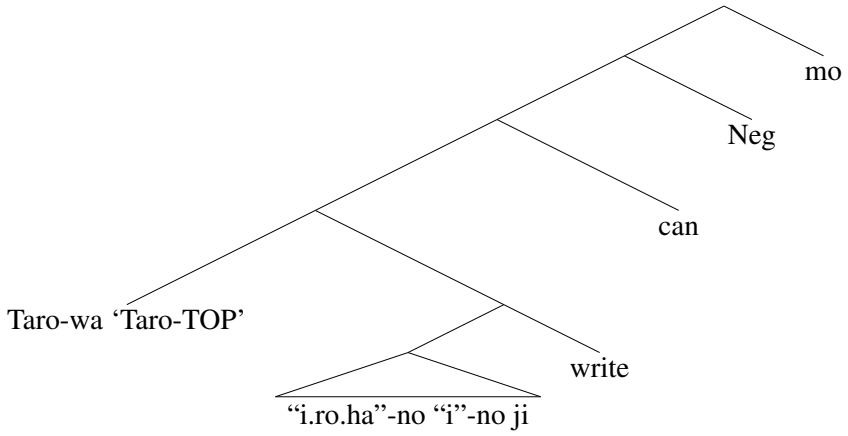

I assume that mo introduces a set of alternative propositions and presupposes that $p$ is the least likely among the relevant alternatives (Karttunen \& Peters 1979), as shown in (22) (Mo also entails that $p$ is an at-issue meaning): 


$$
[[\mathrm{mo}]]=\lambda p: \forall q \in A L T\left[p<_{\mu} q\right] \cdot p
$$

(Note: $\mu$ is a measure function of likelihood. The scalar component is a presupposition.)

Thus, at the final stage of semantic derivation, mo combines with the at-issue proposition in (22a) and we get both the at-issue meaning and the scalar presupposition, as shown in (23):

$$
\begin{aligned}
& \mathrm{MO}\left(\neg \operatorname{can}\left(\text { write }\left(\mathrm{i}<_{\text {part.of }} \text { i.ro.ha }\right)(\text { Taro })\right)\right)=\forall q \in A L T\left[\neg \text { can(write }\left(\mathrm{i}<_{\text {part.of }} \text { i.ro.ha }\right)(\text { Taro })\right) \\
& \left.\left.<_{\mu} q\right] . \neg \text { can(write }\left(\mathrm{i}<_{\text {part.of }} \text { i.ro.ha }\right)(\text { Taro })\right)
\end{aligned}
$$

\section{The meaning and interpretation of the non-literal type.}

5.1 THE NON-LITERAL TYPE REFERS TO THE DEGREE OF A PREDICATE. Let us now analyze the meaning of the non-literal type of mora-based minimizer. As we discussed earlier, the nonliteral type does not have anything to do with the meaning 'a letter'. As the following examples show, the non-literal mora-based minimizer instead has to do with the degree of event or act concerning the target NP ("X.Y.Z." in the form "X.Y.Z.-no X-no ji-mo"):

a. (Degree of knowledge)

Ziro-wa "ge.n.go.ga.ku"-no "ge"-no ji-mo shira-nai.

Ziro-TOP linguistics-GEN GE-GEN letter-even know-NEG

'Ziro does not know anything about linguistics.'

b. (Degree of thought)

Shushou-wa "ka.i.sa.n"-no "ka"-no ji-mo kangae-te i-nai

Prime minister-TOP breakup-GEN KA-GEN letter-even think-TEIRU-NEG

'The prime minister is not thinking about a breakup at all.'

c. (Degree of saying/topic)

Konna jookyoo-nimo kakawarazu shachoo-wa "ka.i.ka.ku"-no

Such situation-despite company president-TOP reformation-GEN

ka-no ji-mo iwa-na-katta.

KA-GEN letter-even say-NEG-PAST

'The company president didn't say anything about a reformation despite a situation like this.'

d. (Degree of capability)

Kare-wa "pu.ro.gu.ra.mi.n.gu"-no "pu"-no ji-mo deki-nai.

He-TOP programming-GEN PU-GEN letter-even can-NEG

'He cannot do programming at all.'

e. (Degree of the act of self-reflection)

Hansei-no ha-no ji-mo nai.

Self-reflection-GEN HA-GEN letter-even exist.NOT

'There is no self-reflection at all. (= He/she/you/they $\{$ does/don't $\}$ not show any selfreflection).'

f. (Degree/frequency of the act of studying)

Taro-wa "be.n.kyo.u"-no "be"-no ji-mo si-na-katta.

Taro-TOP study-GEN BE-GEN letter-even do-NEG-PAST 


\section{'Taro didn't study at all.'}

In the BCCWJ-NT corpus, we can find the following verbs co-occurring with the non-literal type of minimizer:

(25) The verbs that co-occur with a non-literal mora-based minimizer (from BCCWJ-NT corpus): shira-nai 'not know', kuchini si-nai 'don't talk about', iwa-nai 'don't say', kokoroenai 'don't understand', nai 'there is no (not enough)', wakara-nai 'don't know', ukagawasenai 'don't let us think', agara-nai 'don't go up'

Descriptively, it seems that the non-literal mora-based minimizer has the following meaning:

(26) The meaning of the non-literal mora-based minimizer (descriptive): In the non-literal type, the first mora of the mora-based minimizer is construed as a minimum degree with regard to the degree of the main predicate $P$ "about" the targeted expression $\alpha$.

5.2 FORMAL ANALYSIS OF NON-LITERAL MORA-BASED MINIMIZER . Let us now consider the meaning of the mora-based minimizer described in the above in more detail, based on the following example (I assume that gengogaku 'linguistics' has the representation like (28)):

Taro-wa "ge.n.go.ga.ku"-no "ge"-no ji-mo shira-nai. (Non-literal type)

Taro-TOP linguistics-GEN GE-GEN letter-even know-NEG

'Taro does not know anything about linguistics.'

$\langle$ [ge.n.go.ga.ku]; NP; linguistics: $e$ 〉

I propose that a non-literal mora-based minimizer has the following at-issue meaning and alternatives, as in (29):

a. $\left[\left[" \alpha "-n o ~ “ \beta "-n o ~ j i_{\text {non.lit }}\right]\right]=\lambda P_{\langle d,\langle e,\langle e, t\rangle\rangle\rangle} \lambda x . P\left(d_{\text {min }}\right)\left(\alpha_{\text {sem }}\right)(x)$

(presupposition: $\beta_{\text {phon }}=$ the first $\sigma$ of $\alpha_{\text {phon }} \wedge d_{\text {min }}=\beta_{\text {sem }} \wedge d_{\text {min }}=$ the minimum degree of $P$ about $\alpha$ )

b. $\quad[[“ " \alpha \text { "-no " } \beta \text { '-no ji } \text { non.lit }]]_{A L T}=\left\{\lambda P_{\langle d,\langle e,\langle e, t\rangle\rangle\rangle} \lambda x . P(d)\left(\alpha_{\text {sem }}\right)(x): d>d_{\text {min }}\right\}$

(30) shows the interpretation of "ge.n.go.ga.ku-no ge-no ji" in (27):

a. [[ "ge.n.go.ga.ku"-no "ge"-no ji $\left.\left.\mathrm{i}_{\text {non.lit }}\right]\right]=\lambda P \lambda x . P\left(d_{\text {min }}\right)($ linguistics $)(x)$ (presupposition: "ge" = the first $\sigma$ of "ge.n.go.ga.ku" $\wedge d_{\text {min }}=$ sem of "ge" $\wedge d_{\text {min }}$ is the minimum degree of $P$ about linguistics)

b. [[ "ge.n.go.ga.ku"-no "ge"-no ji $\left.\left.{ }_{\text {non.lit }}\right]\right]_{A L T}=\left\{\lambda P \lambda x . P(d)(\right.$ linguistics $\left.)(x): d>d_{\text {min }}\right\}$

Importantly, both the scalarity and the alternatives are dependent on the meaning of the main predicate. For example, if the main predicate is shi-tteiru 'know' as in (31), the alternatives are ranked along the scale of the degree of knowledge about the target.

[[shi-teiru]]: $\langle d,\langle e,\langle e, t\rangle\rangle\rangle=\lambda d \lambda x \lambda y \cdot \operatorname{know}(y)(x)=d$

I assume that the other predicates that appear in the non-literal type are those such as kangaeru 'think', iu 'say' and nai 'not exist', which are also gradable (see also next section).

(32) shows the at-issue proposition and its alternatives. 
(32) a. at-issue meaning: $\neg\left(\right.$ know(Taro)(linguistics) $\left.=d_{\min }\right)$

b. propositional alternatives: $\left\{\neg(\right.$ know(Taro)(linguistics) $\left.=d): d>d_{\min }\right\}$

Just as in the case of the literal type, the non-literal type has the same logical structure; if mo is combined with the at-issue proposition as in (33), we get the scalar presupposition and the at-issue meaning, as shown in (34):

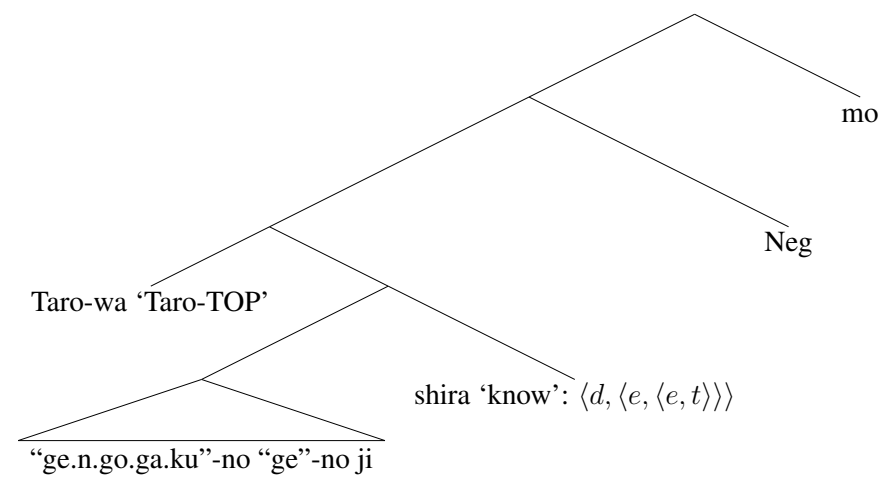

$$
\begin{aligned}
& \operatorname{MO}\left(\neg\left(\text { know }(\text { Taro })(\text { linguistics })=d_{\text {min }}\right)\right)= \\
& \forall q \in A L T\left[\neg\left(\text { know }(\text { Taro })(\text { linguistics })=d_{\text {min }}\right)<_{\mu} q\right] . \neg\left(\text { know }(\text { Taro })(\text { linguistics })=d_{\text {min }}\right)
\end{aligned}
$$

5.3 EXAMPLE WITH AN EVENTIVE NOUN AND A PREDICATIVE $n a i$ 'LIT. NOT EXIST'. Let us now analyze an example with predicative nai 'not exist':
"Hansei"-no
"ha"-no ji-mo nai.
Self-reflection-GEN HA-GEN letter-even exist.NOT
'There is no self-reflection at all.'

We can say that similarly to the other cases, here the predicate nai behaves as a gradable predicate and posits a degree of existence ( $v$ is a type for an event and $e$ is a variable for the type $v):^{5}$

$$
\left[\left[\text { nai }_{P R E D}\right]\right]:\langle d,\langle v, t\rangle\rangle=\lambda d \lambda e . \neg(\operatorname{exist}(e)=d)
$$

I assume that noun hansei denotes an event of type $v$ :

$$
\langle\text { [ha.n.se.i]; NP; self-reflection: } v\rangle
$$

This leads us to posit a slightly different lexical item for a non-literal mora-based minimizer, as in (38), and to posit a structure like (39):
a. $\quad\left[\left[“ \alpha "-n o ~ “ \beta ”-n o ~ j i_{\text {non.lit }}\right]\right]=\lambda P_{\langle d,\langle v, t\rangle\rangle} \cdot P\left(d_{\text {min }}\right)\left(\alpha_{\text {sem }}\right)$
(presupposition: $\beta_{\text {phon }}=$ the first $\sigma$ of $\alpha_{\text {phon }} \wedge d_{\text {min }}=\beta_{\text {sem }} \wedge d_{\text {min }}=$ the minimum degree of $P$ about $\alpha$ )
b. $\quad[[“ \alpha "-\text { no “ } \beta \text { "-no ji } \text { non.lit }]]_{A L T}=\left\{\lambda P_{\langle d,\langle v, t\rangle\rangle} \cdot P(d)\left(\alpha_{\text {sem }}\right): d>d_{\text {min }}\right\}$

\footnotetext{
${ }^{5}$ This idea is supported by the fact that various degree adverbs such as mattaku can co-occur with the predicative nai(Sawada 2008):

(i) Hansei-ga $\quad\{$ mattaku/sukoshi-mo $\}$ nai.

Self-reflection-GEN at all/a bit-even exist.NOT

'There is no self-reflection at all.'
} 


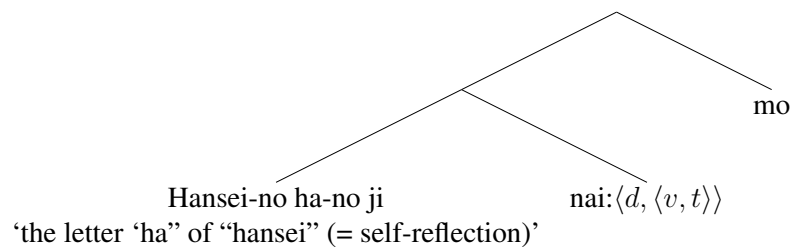

5.4 The nON-Literal type CAN TARget a SPEeCH ACT. An interesting point is that the nonliteral mora-based minimizer can also target a speech act that consists of one word (not just an individual/event-denoting noun):

"A.ri.ga.to.u"-no "a"-no ji-mo na-katta.

"Thank you"-GEN A-GEN letter-even exist.NOT-PAST

'There was no act of thanks at all.'

Kare-wa "go.me.n.na.sa.i"-no "go"-no ji-mo iwa-na-katta.

He-TOP "I am sorry"-GEN GO-GEN letter-even say-NEG-PAST

'He didn't apologize at all.'

This suggests that the denotation of the non-literal mora-based minimizers is quite flexible.

5.5 THE ODD EXAMPLES: THE DIFFERENCE FROM ORDINARY MINIMIZERS. Unlike the ordinary minimizer 'one'-EVEN NPIs, non-literal mora-based minimizers do not fit with the measurement of quantity/amount of the target noun itself.

a. ??Ziro-wa "ri.n.go"-no "ri"-no ji-mo tabe-naka-tta.

Ziro-TOP apple-GEN RI-GEN letter-even eat-NEG-PAST

'Intended: Ziro didn't eat even one apple/Ziro didn't eat a single bite of the apple.'

b. Ziro-wa ringo-o \{hito-tsu-mo/hito-kuchi-mo $\}$ tabe-naka-tta.

Ziro-TOP apple-ACC 1-CL-even/one-bite-even eat-NEG-PAST

'Ziro didn't eat even one apple/Ziro didn't eat a single bite of the apple.'

a. ??Kyoushitsu-ni-wa gakusei-no ga-no ji-mo i-nai.

Classroom-LOC-TOP student-GEN GA-GEN letter-even be-NEG

'Intended: There aren't any students in the classroom.'

b. Kyoushitsu-ni-wa gakusei-ga hito-ri-mo i-nai.

Classroom-LOC-TOP student-NOM one-CL-even be-NEG

'There is not even one student in the classroom.'

We can explain the oddness of (42a) and (43a) based on the semantics of the non-literal mora-based minimizer. These sentences are odd because they measure degrees "about" apples and students, not their quantity. (42a) expresses that Ziro did not eat the minimum degree "about" the apple, and (43a) expresses that there is no degree of existence "about" students.

Notice that if we replace the verbs taberu 'eat' and iru 'be' in (42a) and (43b) with wadai-ni naru 'become the subject', then the sentences with mora-based minimizers become natural:
Kaigi-de-wa
\{ "ri.n.go"-no ri-no
ji-mo
/ gakusei-no ga-no
Meeting-LOC-TOP apple-GEN RO-GEN letter-even / student-GEN GE-GEN 
ji-mo\} wadai-ni nara-na-katta.

letter-even topic-to become-NEG-PAST

"At the meeting not even \{"ri" of "ringo"/"ga" of "gakusei"\} did it become the subject. (= There are no discussions on apple/student at all.)

The above sentences are natural because they refer to the degree of conversation "about" the apple/student.

6. Theoretical implications: Local vs. global minimizers. The phenomenon of the mora-based minimizer suggests that there are two kinds of minimizers in natural language, local minimizers and global minimizers. The local minimizer lexically specifies a scalar meaning, and scalar alternatives are specified inside the lexicon. On the other hand, a global minimizer relies on the information in a predicate in order to specify a scale. More specifically, the global minimizer relies on the information of a predicate in order to specify the dimensions of a scale and activate scalar alternatives. Let us consider this point in detail. Here I assume that a scale is a triple of the following form:

(45) The ontology of scale

$\langle\mathrm{D} ;>$; DIM $\rangle$ where $\mathrm{D}$ is a set of points, $>$ is a total ordering on $\mathrm{D}$, and DIM is a dimension

(e.g., Bartsch \& Vennemann 1973; Bierwisch 1989; Kennedy 2007; Kennedy \& McNally 2005; Solt 2015).

For example, we can say that give a damn belongs to a local minimizer in that it lexically specifies a dimension of a scale:

(46) John doesn't give a damn.

"To give a damn" lexically posits a scale/dimension of care/concern. Chierchia (2013) defines the meaning of give a damn as follows:

a. $\quad$ give a damn $n_{w}=\lambda x \exists s\left[\operatorname{care}_{w}\left(s, x, d_{\text {min }}\right)\right]$

b. $\quad$ ALT (give a damn $)=\left\{\lambda x \exists s\left[\operatorname{care}_{w}\left(s, x, d_{\text {min }}\right)\right]: d^{\prime}>d_{\text {min }}\right\}$

(Chierchia 2013: 150)

However, the non-literal mora-based minimizer does not lexically specify a dimension of a scale, but only signals that the first mora corresponds to a minimum degree.

\section{Mora-based minimizers in other languages and related phenomena.}

7.1 BOSNIAN/CROATIAN/SERBIAN. Interestingly, the mora-based minimizer is not a languagespecific phenomenon. Wayles Browne (p.c.) commented that there is a mora-based minimizer in Bosnian/Croatian/Serbian. The following examples are from the book/articles written by Midhat Ridjanovic (Wayles Browne, p.c.):

(48) ni jedan od tri autora ove knjige nema u sebi ni 'k' od kreativnosti, not-even one of three authors of-this book not-has in self not-even ' $k$ ' of kreativnost 'Not even one of the three authors of this book has in himself even the 'c' of creativity' (From Midhat Ridjanovic "Totalni promaaj lingvistike na Zapadnom Balkanu”, 3rd edition, pp. 135, available at $h t t p s: / / w w w . a c a d e m i a . e d u / 34540671 /$ Totalni $i_{p}$ roma) 
on nije ni ' 1 ' od lingviste

he is-not not-even ' 1 ' of linguist

'He is not even the ' 1 ' of a linguist'

(50) Mi imamo 14 "ministarstava” za nauku, a nemamo ni 'n' od nauke....

We have 14 "ministries" for science, but we-not-have not-even 'n' of science

'We have 14 "ministries" of science, but we don't have even the 's' of science.'

7.2 RELATED BUT DIFFERENT PHENOMENA. Furthermore, there are related but somewhat dif-ferent expressions in Japanese and English, NP-no iroha in Japanese and "the ABCs of an NP" in English. As we observed earlier, iroha means the first three letters of the old-style Japanese hiragana system (a poem). However, iroha also has a meaning "the basics of things" and in some examples, we can paraphrase the sentences of non-literal mora-based minimizers using iroha in NP-no iroha 'the basics of an NP':
a. Taro-wa gengogaku-no iroha-mo shira-nai. Taro-TOP linguistics-GEN basics-even know-NEG 'Taro doesn't even know the basics of linguistics.'
b. Taro-wa "ge.n.go.ga.ku"-no "ge"-no ji-mo shira-nai. Taro-TOP linguistics-GEN GE-GEN letter-even know-NEG 'Taro doesn't even know ge of ge.n.go.ga.ku (=linguistics).'

However, NP-no iroha is more restricted than non-literal mora-based minimizers in that it can only be used in the context where a scale of mastery/skill is relevant. For example, (52b) sounds odd due to the mismatch between the meaning of the verb and the meaning of iroha:
a. Shushoo-wa "ka.i.sa.n"-no ka-no ji-mo iwa-na-katta.
Prime minister-TOP breakup-GEN KA-GEN letter-even say-NEG-PAST
'The prime minister didn't even say ka of ka.i.sa.n (=breakup).'
b. ??Shushoo-wa kaisan-no iroha-mo iwa-na-katta.
Prime minister-TOP breakup-GEN basic-even say-NEG-PAST
'Intended: The prime minister didn't say anything about a breakup.'

Since NP-no iroha lexically posits a scale/dimension of "mastery/level", we can say that it constitutes a local minimizer.

Interestingly, English "the $\mathrm{ABC}$ " can also mean "the basics" and posits a scale of degree of mastery:

a. But clearly, she doesn't even know the ABCs of her job.

(http://www.renewamerica.com/columns/duke/121018)

b. It's almost like they don't even know the ABC of security. (https://www.awsforbusiness.com/abc-confirms-aws-s3-data-leak/)

Theoretically, English "the ABCs" can also be regarded as local rather than global minimizers.

8. Conclusions. This paper investigated the meanings of literal and non-literal types of morabased minimizer and showed that each has a different semantic mechanism for computing a scale and alternatives. The phenomenon of the non-literal use of a mora-based minimizer is theoretically 
important because unlike regular minimizers and literal mora-based minimizers, the minimum degree in a non-literal mora-based minimizer and its alternatives are not lexically determined (i.e., they are instead specified by utilizing the scale/dimension associated with a main predicate). This paper proposed that in addition to a local minimizer whose alternatives are lexically activated (Chierchia 2013), there is a global minimizer in natural language, the alternatives of which are activated by information contained in the main predicate. I hope this paper will shed new light on variation in the meaning of minimizers.

In future work, I would like to further investigate the interpretation of non-literal mora-based minimizers from a quantitative perspective, using corpus data. It seems that non-literal mora-based minimizers often co-occur with intensional predicates such as shi-teiru 'know', iu 'say.' Furthermore, I would like to consider the pragmatic function of mora-based minimizers in more detail. Mora-based minimizers are often used in the object of the verb and often express a speaker's negative emotion toward a third-person subject or an implicit referent. (It seems that it is difficult to put "X.Y.Z"-no "X"-no ji-mo 'even the letter "X" of "X.Y.Z' in the agentive subject position; Mitcho Erlewine, personal communication.) Scalar expressions are often used as expressives (Sawada 2018), and this phenomenon may also be related to the nature of expressives/anti-honorifics.

Finally, a more detailed discussion will be necessary on the relationship between the literal and non-literal types of mora-based minimizers. In this paper I claimed that they are lexically different, but there must be a semantic connection between the two as well. It seems plausible to consider that the non-literal reading developed though the conventionalization of a pragmatic inference triggered by a literal reading.

\section{References}

Artstein, Ron. 2004. Focus below the word level. Natural Language Semantics 12. 1-22.

Bartsch, Renate \& Theo T. Vennemann. 1973. Semantic structures: A study in the relation between syntax and semantics. Frankfurt: Athäenum Verlag.

Bierwisch, Manfred. 1989. The semantics of gradation. In Manfred Bierwisch \& Ewald Lang (eds.), Dimensional adjectives, 71-261. Berlin: Springer Verlag.

Bolinger, Dwight. 1972. Degree Words. Paris: Mouton.

Chierchia, Gennaro. 2013. Logic in grammar: Polarity, free choice, and intervention. Oxford: Oxford University Press.

Csipak, Eva, Regine Eckardt, Mingya Liu \& Mandred Sailer. 2013. Beyond 'any' and 'ever': New explorations in negative polarity sensitivity. Berlin: Mouton de Gruyter.

Giannakidou, Anastasia. 1998. Polarity sensitivity as (non)veridical dependency. Amsterdam: John Benjamin.

Giannakidou, Anastasia. 2011. Positive polarity items and negative polarity items: variation, licensing, and compositionality. In Claudia Maienborn, Klaus von Heusinger \& Paul Portner (eds.), Semantics: An international handbook of natural language meaning. 1660-1712. Berlin: Mouton de Gruyter.

Heim, Irene. 1984. A note on negative polarity and downward entailingness. In Proceedings of the 14th meeting of the North East Linguistic Society (NELS). 98-107.

Karttunen, Lauri \& Stanley Peters. 1979. Conventional implicature. In C. K. Oh \& D. A. Dinneen (eds.), Syntax and semantics. Vol. 11. Presupposition. 1-56. New York: Academic Press. 
Kennedy, Christopher. 2007.Vaguness and grammar: the semantics of relative and absolute and gradable adjectives. Linguistics and Philosophy 30(1). 1-45.

https://doi.org/10.1007/s10988-006-9008-0.

Kennedy, Christopher \& Louise McNally. 2005. Scale structure, degree modification, and the semantics of gradable predicates. Language 81. 345-381. https://doi.org/110.1353/ lan.2005.0071.

Kratzer, Angelika \& Junko Shimoyama. 2002. Indeterminate pronouns: the view from japanese. In Yukoi Otsu (ed.), Proceedings of the third tokyo conference on psycholinguistics, 1-25.

Krifka, Manfred. 1995. The semantics and pragmatics of polarity items. Linguistic Analysis 25. $1-49$.

Ladusaw, William. A. 1980. Polarity sensitivity as inherent scope relations. New York \& London: Garland Publishing.

Lahiri, Utpal. 1998. Focus and negative polarity in hindi. Natural Language Semantics 6. 57-123. https://doi.org/10.1023/A:100821180.

Lee, Young-Suk \& Laurence Horn. 1994. Any as indefinite plus even. Manuscript, Yale University.

Li, Haoze. 2017. Semantics of metalinguistic focus. In Alexandre Cremers, Thom van Gessel \& Floris Roelofsen (eds.), Proceedings of the 21st Amsterdam Colloquium. 345-354.

Niino, Naoya. 1993. Juunen hayai, 'too early' nani ga kanashikute 'why do i need to'. Nihongogaku 12(7). 29-33.

Rochemont, Michael. S. 1986. Focus in generative grammar. Amsterdam: John Benjamins.

Rooth, Mats. 1992. A theory of focus interpretation. Natural Language Semantics 1. 75-116. https://doi.org/10.1007/BF02342617.

Sawada, Osamu. 2008. Two types of adverbial polarity items in japanese: absolute and relative. Proceedings of the 10th Conference of the Pragmatics Society of Japan. 263-270.

Sawada, Osamu. 2018. Pragmatic aspects of scalar modifiers: The semantics-pragmatics interface. Oxford: Oxford University Press.

Selkirk, Elisabeth O. 1984. Phonology and syntax: The relation between sound and structure. Cambridge, Mass: MIT Press.

Solt, Stephanie. 2015. Vagueness and imprecision: Empirical foundations. Annual Review of Linguistics 1. 107-127. 